\title{
Pengaruh Gaya Kepemimpinan, Iklim Organisasi dan Budaya Organisasi Terhadap Prestasi Kerja Pegawai
}

\section{Oddang Oddang1, Ahmad Gani ${ }^{2}$, Ramlawati Ramlawati ${ }^{3}$}

12,3, Magister Manajemen, Universitas Muslim Indonesia.

${ }^{1}$ Koresponden Penulis, E-mail: oddangpadduandi@gmail.com

\begin{abstract}
ABSTRAK
Penelitian ini bertujuan untuk menguji sejauh mana pengaruh gaya kepemimpinan, iklim organisasi dan budaya organisasi terhadap prestasi kerja Badan Kesatuan Bangsa dan Politik Provinsi Sulawesi - Selatan. Pengumpulan data dilakukan melalui penyebaran kuesioner dan dilaksanakan pada 74 pegawai Badan Kesatuan Bangsa dan Politik Provinsi Sulawesi - Selatan. Analisis data pada penelitian ini menggunakan bantuan program SPSS versi 20. Teknik sampling yang dipakai adalah metode sensus dan teknik pengujian data yang digunakan dalam penelitian ini meliputi Uji asumsi klasik dan analisis regresi linier berganda, untuk menguji dan membuktikan hipotesis penelitian. Hasil analisis menunjukkan bahwa secara simultan faktor gaya kepemimpinan, iklim organisasi dan budaya organisasi berpengaruh terhadap prestasi kerja pegawai dan secara parsial yang berpengaruh dominan terhadap prestasi kerja pegawai adalah gaya kepemimpinan
\end{abstract}

Kata Kunci: Gaya Kepemimpinan; Iklim Organisasi; Budaya Organisasi,

\section{ABSTRACT}

This study aims to discuss how the influence of leadership style, organizational climate and organizational culture on work performance of the National Unity and Politics of the Sulawesi-South Province. Data was collected through interviews and carried out in 74 offices of the National Unity and Politics Agency of the Province of Sulawesi - South. Data analysis in this study used SPSS version 20 assistance program. The sampling technique used is the census method and the data testing technique used in this study completes the classic Assessing Test and multiple linear regression analysis, to test and prove the research hypothesis. The results of the analysis show that the factors of leadership style, organizational climate and organizational culture on work performance and partial are dominant on employee work Leadership Style.

Keyword: Leadership Style; Organizational Climate; Organizational Culture 


\section{PENDAHULUAN}

Dinamika organisasi yang terus terjadi dalam sebuah perusahaan memiliki konsekuensi tersendiri bagi para manajerial untuk dapat menanggapi setiap perubahan yang terjadi terutama perhatian terhadap Sumber Daya Manusia (SDM) yang berperan penting dalam menentukan aspek keberlangsungan dan pencapaian tujuan perusahaan (Muslim \& Murfat, 2019). Dalam konteks pemerintahan, Pelayanan prima yang diberikan oleh aparat hanya dapat diwujudkan melalui peningkatan kualitas, komitmen dan keberpihakan sebagai pelayan masyarakat dalam barbagai kegiatan pembangunan secara bertahap dengan mengarahkan apparat pemerintah sebagai fasiliator dengan memberi pelayanan maksimal kepada masyarakat (Syamsir \& Ramlawati, 2019).

Selama ini aparat lebih banyak diarahkan untuk pengisian dan pemenuhan aspek struktural (aselonisasi) dan lebih bersifat manajerial dan prestise bagi seorang aparat sehingga berdampak signifikan terhadap aspek pelayanan yang sulit tercapai. Oleh karena itu untuk mencapai pelayanan maksimal dari instansi pemerintah maka diperlukan sosok pemimpin yang mampu menjadi motor penggerak keberhasilan pelaksanaan tugas pokok organisasi yang terimplementasi dalam rangkaian hierarki organisasi, pemberian pembatasan wewenang dan tugas masing-masing dan adanya komunikasi yang fleksibel dari atasan dan bawahan begitu juga sebaliknya sehingga terjalin hubungan serta memerlukan kerjasama dalam usaha pencapaian tujuan organisasi (Gani, 2009).

Sosok gaya kepemimpinan yang tepat dari seorang pemimpin merupakan perilaku yang menjadi sumber kepuasan bagi para bawahannya. Keterlibatannya gaya kepemimpinan dalam memacu prestasi kerja sudah merupakan nilai dan harga yang sangat berarti dalam mengoperasikan sebuah organisasi. Menurut Siagian, (2002) prestasi kerja setiap individu yang ikut bertanggung jawab dalam organisasi, wajib hukumnya mendapat pembinaan dari atasannya yang terutang dalam system kepemimpinan yang dianutnya.

Berbagai penelitian terdahulu mencoba mengukur prestasi kerja pegawai dengan variable gaya kepemimpinan seperti (Widiartana et al., 2016; Tumbol et al. 2014; Setiawan, 2013) dan menemukan adanya hubungan antara gaya kepemimpinan dan prestasi kerja pegawai. Hasil penelitian ini secara umum menjelaskan bahwa partisipasi dalam gaya kepemimpinan merupakan unsur yang sangat mendasar untuk menjadi seorang pemimpin.

Menurut Ndraha, (2003) suatu organisasi yang memiliki pilar budaya organisasi yang kuat yang didalamnya berisi nilai juang, etos kerja, ciri khas dan dapat membangun sebuah prospektif yang cerah menghadapi berbagai terpaan pengaruh dari faktor-faktor luar suatu organisasi. budaya organisasi esensinya merupakan nilai-nilai juang yang menjiwai etos kerja dari aktualisasi ciri khas yang ditunjukkan oleh setiap orang di dalam memahami norma kerja yang dianutnya. Oleh karena itu perusahaan harus memiliki manajemen yang baik agar mampu membentuk budaya organisasi yang baik sehingga bias bersaing dan memanfaatkan semaksimal mungkin sumber daya yang ada didalam perusahaan agar prestasi kerja yang dihasilkan dapat meningkat (Kastholani, 2017). Sutarso, (2010) memberikan pandangan bahwa diperlukan ketegasan dalam organisasi sehingga terbentuk 


\section{3 | Tata Kelola, Vol.7, No. 1, Juni 2020}

budaya kerja yang mencerminkan spesifikasi suatu orgnisasi. Budaya kerja ini akhirnya untuk seluruh lapisan individu yang ada dalam organisasi yang kemudian akan membentuk budaya organisasi sesuai nilai juang, etos kerja, ciri khas dan norma- norma yang mengikat karakter dan perilaku individu untuk membuat suatu karya atas pandangan budaya organisasi yang dianutnya.

Penelitian ini mengacu pada penelitian Gani, (2006) yang meneliti tentang gaya kepemimpinan, budaya organisasi dan motivasi untuk mengukur hasil kinerja pegawai. Namun penelitian ini berbeda dengan penelitian Gani, (2006) karena dalam penelitian ini terdapat penambahan variable baru yakni variable iklim organisasi untuk mengukur dan mengkaji pengaruhnya terhadap prestasi kerja pegawai. Alasan penggunaan iklim organisasi dalam penelitian ini adalah karena dalam sebuah organisasi, Iklim organisasi penting untuk diciptakan karena berkaitan tentang persepsi seorang tentang apa yang diberikan oleh organisasi dan dijadikan dasar bagi penentuan tingkah laku anggota selanjutnya. Iklim ditentukan oleh seberapa baik anggota diarahkan, dibangun dan dihargai oleh organisasi.

Berdasarkan uraian yang telah dijelaskan, maka kerangka konseptual penelitian ini dapat digmbarkan sebagaimana tampilan pada Gambar 1.

\section{Gambar 1. Kerangka Konsep Penelitian}

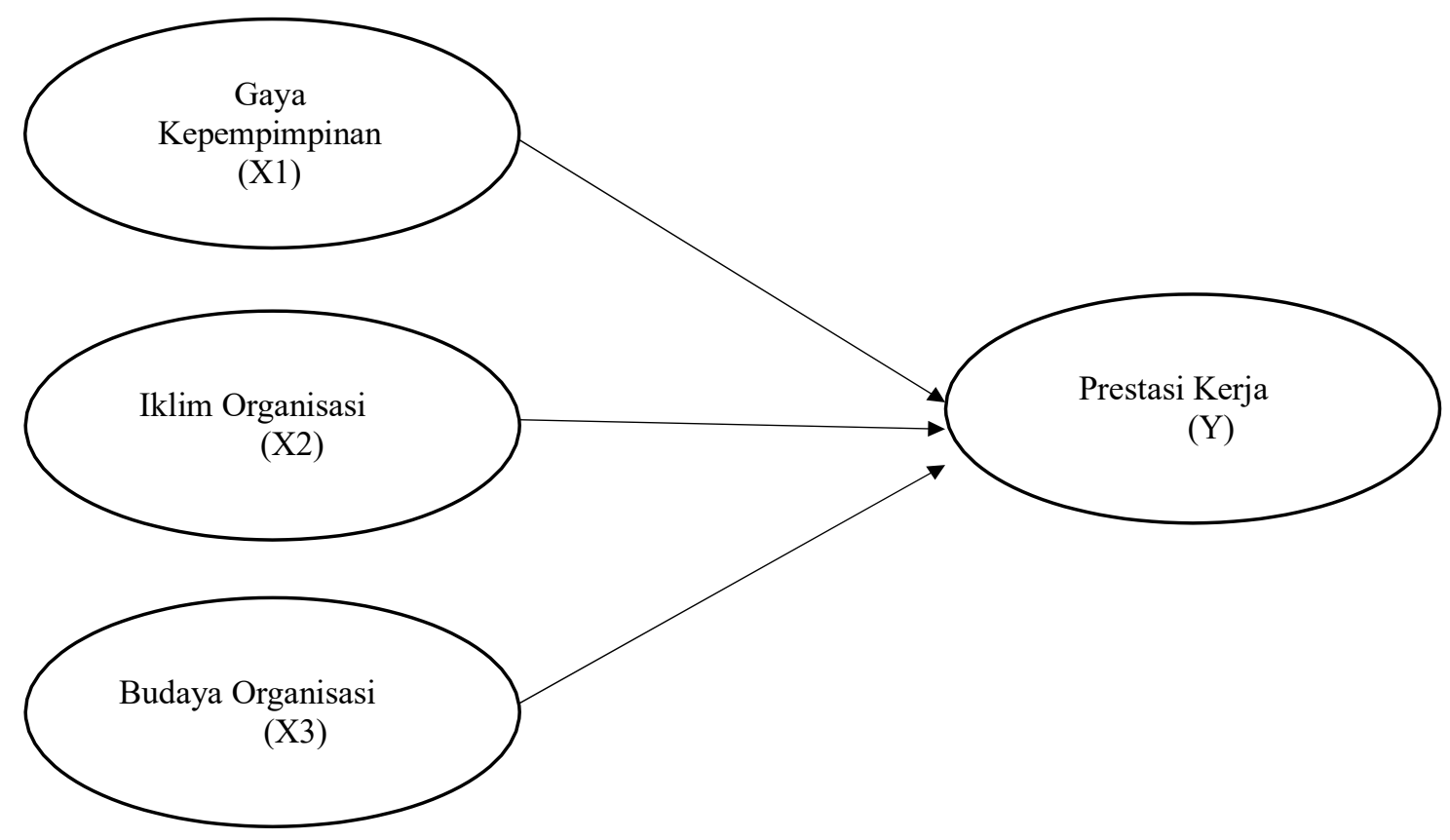


Hipotesis 1: Gaya kepemimpinan Geografis positif dan signifikan terhadap prestasi kerja pegawai Badan Kesbangpol Provinsi Sulawesi Selatan.

Hipotesis 2: Gaya kepemimpinan Demokratis secara signifikan terhadap prestasi kerja pegawai Badan Kesbangpol Provinsi Sulawesi Selatan.

Hipotesis 3: Iklim Organisasi berpengaruh terhadap positif dan signifikan prestasi kerja pegawai Bakesbangpol Provinsi Sulawesi Selatan.

Hipotesis 4: Budaya organisasi berpengaruh terhadap prestasi kerja pegawai Bakesbangpol Provinsi Sulawesi Selatan

\section{METODE PENELITIAN}

Penelitian dilakukan pada Sekretariat Bakesbangpol Propinsi Sulawesi Selatan dengan jumlah populasi sebanyak 74 orang. Penentuan sampel dalam penelitian ini menggunakan metode sensus karena jumlah populasi yang kurang dari 100 (Sugiyono, 2010). Pengumpulan data penelitian dilakukan dengan mendatangi langsung lokasi penelitian untuk mendapatkan data primer melalui penyebaran kuesioner kepada responden. Metode analisis data yang digunakan untuk mengolah data serta menarik kesimpulan penelitian ini dibantu dengan program SPSS versi 24. Data yang berhasil dikumpulkan akan dianalisis dengan beberapa tahap pengujian yaitu uji statistic deskriptif, uji asumsi klasik (Uji normalitas, multikolinearitas, heterokedastisitas) dan pengujian hipotesis dengan pengujian regresi berganda, uji $F$, uji parsial $(\mathrm{t}$ ) dan uji koefisien determinasi.

Untuk menjawab hipotesisi penelitian maka digunakan rumus menggunakan analisis regresi berganda sebagai berikut:

$\mathrm{Y}=\mathrm{a}+\beta 1 \mathrm{X} 1+\beta 2 \mathrm{X} 2+\beta 3 \mathrm{X} 3+\mathrm{e}$

Keterangan:

$\mathrm{Y}=$ Kinerja

a $=$ Intercept

$\beta 1-\beta 3=$ Bilangan Koefisien

$\mathrm{X} 1=$ Gaya Kepemimpinan

$\mathrm{X} 2=$ Iklim Organisasi

X3 = Budaya Organisasi

e $\quad=$ Error estimate

\section{HASIL PENELITIAN DAN PEMBAHASAN}

\section{Hasil}

Berdasarkan data yang diperoleh dari lokasi penelitian, hasil olahan data statistic dari SPSS adalah Hasil analisis uji validasi prestasi kerja diperoleh nilai korelasi 


\section{5 | Tata Kelola, Vol.7, No. 1, Juni 2020}

antara skor item dengan skor total (Corrected Item-Total Correlation). Nilai tersebut dibandingkan dengan rtabel pada signifikasi 0,05 denga uji 2 sisi dan jumlah data (n) $=30-2$, maka diperoleh $\mathrm{r}$ tabel sebesar 0,361. Secara keseluruhan item pernyataan dapat disimpulkan bahwa item pernyataan adalah valid.

Hasil koefisien Regresi diperoleh hasil persamaan regresi untuk penelitian ini adalah sebagai berikut:

Tabel 11: Model Summary

\begin{tabular}{lccc}
\hline Variabel & Koefisien regresi & $\mathbf{t}_{\text {hitung }}$ & Sig \\
\hline Constanta & $-0,239$ & - & - \\
Gaya Kepemimpinan $(X 1)$ & 0,690 & 5,217 & 0,000 \\
Iklim Organisasi (X2) & 0,086 & 1,115 & 0,269 \\
Budaya Organisasi (X3) & 0,272 & 2,496 & 0,015 \\
R & 0,851 & - & - \\
$\mathrm{R}^{2}$ & 0,725 & - & - \\
Fhitung & 61,376 & - & 0,000 \\
\hline
\end{tabular}

Sumber: Data olahan SPSS (2020)

Dari persamaan tersebut dapat disimpulkan sebagai berikut:

a. Konstanta $(\mathrm{b} 0)=-0,239$, menunjukkan harga konstan, di mana jika nilai variabel Independen $=0$, maka diperoleh nilai Prestasi kerja $(Y)=-0,239$.

b. Koefisien X1 (b1) = 0,690, menunjukkan bahwa variabel gaya kepemimpinan $(\mathrm{X} 1)$ berpengaruh positif terhadap Prestasi kerja (Y). Dengan kata lain, jika variabel gaya kepemimpinanditingkatkan sebesar satu maka Prestasi kerja akan bertambah sebesar 0,690. Nilai sig : 0,393< < : 0,05, kesimpulannya adalah $\mathrm{H}_{0}$ ditolak dan $\mathrm{H}_{1}$ diterima yang berarti koefisien kemampuan signifikan secara statistik.

c. Koefisien X2 (b1) = 0,086, menunjukkan bahwa variabel Iklim Organisasi (X2) berpengaruh positif terhadap Prestasi kerja (Y). Dengan kata lain, jika variabel Iklim Organisasi ditingkatkan sebesar satu maka Prestasi kerja akan bertambah sebesar 0,086. Nilai sig : 0,269 < a : 0,05, kesimpulannya adalah $\mathrm{H}_{0}$ ditolak dan $\mathrm{H}_{1}$ diterima yang berarti koefisien Iklim Organisasi signifikan secara statistik

d. Koefisien X3 (b3) = 0,272, menunjukkan bahwa variabel Budaya Organisasi (X2) berpengaruh positif terhadap Prestasi kerja (Y). Dengan kata lain, jika variabel Budaya Organisasi ditingkatkan sebesar satu maka Prestasi kerja akan bertambah sebesar 0,272. Nilai sig : 0,000< < : 0,05, kesimpulannya adalah $\mathrm{H}_{0}$ ditolak dan $\mathrm{H}_{1}$ diterima yang berarti koefisien budaya organisasi signifikan secara statistik.

Pengujian hipotesis dilakukan secara bersama-sama (simultan) dan secara parsial. Pengaruh variabel independen terhadap variabel dependen diuji dengan tingkat kepercayaan $95 \%$ atau d $=5 \%$. Hasil uji simultan (Uji F) dapat diketahui bahwa Nilai 
Fhitung $=61,376$ dan Ftabel $=3.16$, dalam hal ini jika Fhitung $>$ Ftabel dan nilai signifikan adalah 0.000 lebih kecil dari nilai alpha 0.05. sehingga keputusan yang diambil adalah $\mathrm{H} 0$ ditolak dan $\mathrm{H} 1$ diterima. Artinya Gaya Kepemimpinan (X1), Iklim Organisasi (X2) dan Budaya Organisasi (X3), secara simultan berpengaruh signifikan terhadap Prestasi kerja (Y).

Hasil pengujian secara parsial, menunjukkan hasil:

a. Nilai thitung untuk variabel gaya kepemimpinan 5,217 lebih besar dibandingkan dengan t-tabel 1,667 dan Nilai Signifikan kemampuan sebesar $0,008(0,008<0,05)$. Dengan demikian karena probabilitas lebih kecil dari 0,05 maka $\mathrm{H}_{0}$ ditolak. Artinya kemampuan (X1) secara parsial berpengaruh signifikan terhadap Prestasi kerja $(\mathrm{Y})$

b. Nilai thitung untuk variabel Iklim Organisasi 1,115 lebih besar dibandingkan dengan $t_{\text {tabel }} 1,667$ dan Nilai Signifikan budaya organisasi sebesar 0,037 (0,037 $<0,05)$. Dengan demikian karena probabilitas lebih kecil dari 0,05 maka $\mathrm{H}_{0}$ ditolak. Artinya Iklim Organisasi (X3) secara parsial berpengaruh signifikan terhadap Prestasi kerja $(\mathrm{Y})$

c. Nilai thitung untuk variabel budaya organisasi 2,496 lebih besar dibandingkan dengan $t_{\text {tabel }} 1,667$ dan Nilai Signifikan budaya organisasi sebesar 0,049 (0,049 $<0,05)$. Dengan demikian karena probabilitas lebih kecil dari 0,05 maka $\mathrm{H}_{0}$ ditolak. Artinya budaya organisasi (X2) secara parsial berpengaruh signifikan terhadap Prestasi kerja (Y)

\section{Pembahasan}

\section{Pengaruh Gaya Kepemimpinan terhadap Prestasi kerja}

Hasil penelitian menunjukkan bahwa Gaya Kepemimpinan berpengaruh positif terhadap variabel Prestasi Kerja yang berarti apabila Gaya Kepemimpinan semakin ditingkatkan maka dapat meningkatkan Prestasi Badan Kesatuan Bangsa dan Politik Provinsi Sulawesi Selatan. Hal ini mempunyai makna bahwa untuk meningkatkan prestasi kerja pegawai Badan Kesatuan Bangsa dan Politik Provinsi Sulawesi Selatan, maka pimpinan perlu menerapkan gaya kepemimpinan pada orientasi tugas dimana pimpinan perlu memberikan pengarahan kepada pegawai sebelum melaksanakan pekerjaan, menetapkan peraturan yang harus ditaati sehingga tujuan yang sudah ditetapkan dapat tercapai.

Temuan ini mendukung hasil penelitian sebelumnya yang dilakukan oleh Kiswanto (2010) dengan hasil variabel kepemimpinan mempunyai pengaruh positif kepada kinerja pegawai. Penelitian yang dilakukan oleh Garcia \& Victor (2008) menunjukkan bahwa kepemimpinan menunjukkan pengaruh positif antara kepemimpinan dengan prestasi karyawan. Penelitian lain yang mendukung dilakukan oleh Li Chung Kai (2009) menunjukkan bahwa kepemimpinan memiliki efek baik terhadap kinerja karyawan. 


\section{Pengaruh Iklim Organisasi terhadap Prestasi kerja}

Hasil penelitian ini menunjukkan Iklim Organisasi berpengaruh positif dan signifikan kepada Prestasi Kerja yang berarti Iklim Organisasi yang baik dapat meningkatkan prestasi kerja karyawan. Hasil ini menggambarkan bahwa fakta yang terjadi dilapangan yaitu pegawai Badan Kesatuan Bangsa dan Politik Sulawesi Selatan memiliki dorongan Iklim Organisasi untuk berprestasi cukup tinggi, peningkatan golongan/kepangkatan yang sesuai dan suasana kantor yang kondusif dikarenakan pimpinan atau kepala badan memberikan penilaian prestasi kerja pegawai setiap tahun, penempatan pegawai sesuai dengan golongan dan eselon, penetapan gaji, tunjangan dan kesejahteraan Pegawai Negeri Sipil Daerah sesuai dengan norma, standar dan prosedur yang ditetapkan dengan ketentuan perundangundangan yang berlaku, hubungan kerja yang antara sesama pegawai dan pimpinan sangat baik dalam suasana kekeluargaan dan saling menghormati.

Temuan ini mendukung hasil penelitian sebelumnya yang dilakukan oleh Jarunee et al., (2010) terbukti bahwa iklim organisasi berpengaruh secara signifikan terhadap prestasi kerja karyawan.Penelitian lain yang mendukung dilakukan oleh Suryo (2010) menunjukkan bahwa iklim organisasi memiliki hubungan yang signifikan terhadap prestasi kerja karyawan.

\section{Pengaruh Budaya Organisasi terhadap Prestasi Kerja}

Hasil penelitian ini menunjukkan budaya organisasi secara parsial berpengaruh signifikan terhadap Prestasi kerja yang berarti bahwa budaya organisasi yang baik dapat meningkatkan prestasi kerja yang dicapai oleh pegawai Badan Kesatuan Bangsa dan Politik Sulawesi Selatan. Budaya organisasi memiliki peran dalam memberi identifikasi dan prinsip-prinsip yang mengarahkan perilaku organisasi dan dalam membuat keputusan, mengembangkan suatu metode sehingga individu dapat menerima feedback atas prestasi mereka, menjaga sistem reward dan reinforcement yang diberlakukan dalam organisasi.

Hasil ini mendukung penelitian Brahmasari, \& Suprayetno, (2008); Dewanggana et al., (2016) yang menemukan pengaruh antara budaya organisasi dan prestasi kerja pegawai.

\section{KESIMPULAN}

Hasil penelitian ini menemukan bahwa secara parsial maupun simultan variabel gaya kepemimpinan, iklim organisasi dan budaya organisasi berpengaruh terhadap prestasi kerja pegawai Badan Kesatuan Bangsa dan Politik Sulawesi Selatan. Berdasarkan hasil dari karakterisitk responden dn hasil analisis data pada pengujian hipotesis secara parsial, hasil penelitian ini menyarankan agar Pemerintah Provinsi dan Kepala Badan sebaiknya lebih mendorong peningkatan kemampuan, budaya organisasi, dan motivasi agar Prestasi kerja dalam pelayanan kepegawaian pada Badan Kesatuan Bangsa dan Politik Provinsi Sulawesi Selatan semakin meningkat, misalnya, melalui pendidikan dan pelatihan kepemimpinan, peningkatan insetif dan bonus kesejahteraan, melengkapi fasilitas pegawai. Hasil penelitian ini jga 
menyarankan kepada peneliti selanjutnya agar dapat menggunakan variabel lain dalam mengukur prestasi kerja pegawai agar wawasan tentang faktor-faktor yang dapat mempengaruhi prestasi kerja pegawai dapat bertambah.

\section{DAFTAR PUSTAKA}

Brahmasari, I. A., \& Suprayetno, A. (2008). Pengaruh motivasi kerja, kepemimpinan dan budaya organisasi terhadap kepuasan kerja karyawan serta dampaknya pada kinerja perusahaan (Studi kasus pada PT. Pei Hai International Wiratama Indonesia). Jurnal Manajemen dan kewirausahaan, 10(2), 124-135.

Dewanggana, B. D., Paramita, P. D., \& Haryono, A. T. (2016). Pengaruh Komitmen Organisasi, Kepuasan Kerja, Budaya Organisasi terhadap Organizational Citizenship Behavior (OCB) yang Berdampak pada Prestasi Kerja Karyawan (Studi pada PT. PLN App Semarang). Journal of Management, 2(2).

Gani, A. (2006). Pengaruh gaya Kepemimpinan, Budaya organisasi dan Motivasi kerja terhadap kinerja karyawan Industri kayu olahan di kota makasar. Disertasi. Malang: Universitas Brawijaya. Tidak ditcrbitkan.

Gani, A. (2009). Analisis faktor-faktor yang mempengaruhi kinerja pegawai kantor pelayanan pajak bumi dan bangunan kota Makassar. Jurnal Aplikasi Manajemen, 7(1), 220-228.

Garcia-Morales, Victor J. 2008. Influence Of Transformational Leadership On Organizational Innovation andPerformance Depending On The Level Of Organizational Learning In The Pharmaceutical Sector.Journal of Organizational Change Management, 21 (2) : pp: 188-212.

Kastholani, D. (2017). Pengaruh Penghargaan dan Budaya Organisasi Terhadap Prestasi Kerja Karyawan (Studi Pada PT Aryaguna Putra Yogyakarta) (Doctoral dissertation, Universitas Lampung).

Kiswanto, M. 2010. Pengaruh Kepemimpinan dan Komunikasi terhadap Kinerja Karyawan Kaltim Pos Samarinda Jurnal Eksis. Vol. 6, No. 1. Halaman 14291439.

Muslim, M., \& Murfat, M. Z. (2019). Sistem pendukung keputusan seleksi karyawan baru (Issue June). Sefa Bumi Persada.

Ndraha, T. (2003). Teori Budaya Organisasi, Cetakan Kedua. Jakarta: PT. Rineka Cipta.

Setiawan, A. H. (2013). Pengaruh Gaya Kepemimpinan, Kepuasan Kerja Dan Motivasi Terhadap Prestasi Kerja Karyawan CV Bintang Putra Djokdja. Jurnal Manajemen, 3(1), 1-7.

Siagian, S. P. (2002). Kiat meningkatkan produktivitas kerja. Jakarta: Rineka Cipta.

Sugiyono, P. D. (2010). Metode penelitian pendidikan. Pendekatan Kuantitatif.

Suryo, Bikhu Dharma. 2010. Pengaruh Gaya Kepemimpinan transformasional, Budaya Organisasi dan Inovasi Terhadap Kinerja. Jurnal Aplikasi Manajemen, 8 (2): h: 391-403. 
Sutarso, J. (2010). Eksistensi Organisasi Negara Dalam Era Global: Perspektif Budaya. Syamsir, M., \& Ramlawati, R. (2019). Pengaruh Kompetensi, Motivasi, dan Kepemimpinan Terhadap Kinerja Pegawai Dinas Pertanian dan Ketahanan Pangan Kabupaten Kepulauan Selayar. MANOR: JURNAL Manajemen dan Organisasi Review, 1(2), 89-100.

Tumbol, C. L., Tewal, B., \& Sepang, J. L. (2014). Gaya kepemimpinan otokratis, demokratik dan laissez faire terhadap peningkatan prestasi kerja karyawan pada KPP Pratama Manado. Jurnal EMBA: Jurnal Riset Ekonomi, Manajemen, Bisnis dan Akuntansi, 2(1).

Widiartana, W., Zukhri, A., Sujana, I. N., \& Si, M. (2016). Pengaruh Gaya Kepemimpinan dan Motivasi Kerja Terhadap Prestasi Kerja Karyawan Pada UD. Sinar Abadi. Jurnal Pendidikan Ekonomi Undiksha, 6(1). 